\title{
Ellagic Acid - Chemopreventive Role in Oral Cancer
}

\author{
Prakash S Bisen ${ }^{1 *}$, Saurabh S Bundela ${ }^{1,2}$ and Anjana Sharma ${ }^{2}$
}

${ }^{1}$ Defence Research Development Establishment, Defence Research Development Organization, Ministry of Defence, Govt. of India, Jhansi Road, Gwalior 474002, India ${ }^{2}$ Department of Postgraduate Studies \& Research in Biological Sciences, Rani Durgavati University, Jabalpur 482001, India

\begin{abstract}
Ellagic acid is an antioxidant and an anti-proliferative compound present in fruits, nuts and vegetables. In spite of evidences for anticancer activity in various cancer cell-lines, human cancer cells, the mechanistic role of ellagic acid is not conclusive enough to be recommended for a clinical use. The present review provides information about the chemopreventive role of ellagic acid in oral cancer and proposes molecular basis for ellagic acid's inhibitory activity against oral cancer. We show that ellagic acid modulates growth of tumor cells through regulation of multiple cell signaling pathways including cell proliferation pathway (cyclin dependent kinase 2, cyclin A2, cyclin B1, cyclin D1, c-myc, PKC $\alpha$ ), cell survival/apoptosis pathway (Bcl-XL, Bax, Caspase 9/3, Akt), tumor suppressor pathway (p53, p21), inflaming Metastasis pathways (IL-1 beta, TNF- $\alpha$, matrix metalloproteinases $9 / 3$, COX-2), angiogenesis pathways (VEGF), cell immortalization (TERT), NF-K $\beta$.
\end{abstract}

Keywords: Oral cancer; Ellagic acid; Ellagitannins; Urolithins; Angiogenesis; Molecular targets; Cancer hallmarks

\section{Introduction}

Oral cancer is the $10^{\text {th }}$ most common form of cancer worldwide. Developing countries share major global burden of deaths due to oral cancer; countries like India contributes 26\% of global oral cancer incidence. Oral cancer is $2^{\text {nd }}$ most common form of cancer among Indian males [1]. Oral cancer is a multi-factorial disease which has implicating attributes like genetics, environmental, life-style and behavioral [2]. Around half of the patients detected for oral cancer will die within 5 years of initial diagnosis. Five year survival rate has not improved in spite of better understanding of cancer at a molecular level and with the advent of rationally targeted drugs [3].

Oral cancer is managed through various approaches like surgery and radiation, which can be used alone or in combination, often with chemotherapy. Chemotherapeutic drugs come with a downside of indiscriminately killing normal cells along with the intended cancer cells. Newer therapeutic approaches use targeted drugs to specifically target cancer cell by exploiting subtle differences between cell types at a molecular level. Such targeted drugs approved for oral cancer treatment, works by targeting important events associated with oral carcinogenesis; blocker agent like Cetuximab [4] acts by blocking entry of growth factor through epidermal growth factor receptor (EGFR), which thereby prevents tumorous cell growth, another set of agents like Bevacizumab acts by targeting vascular endothelial growth factor (VEGF), a critical biomolecule necessary for angiogenesis. The efficacy of these targeted agents has been demonstrated to depend on presence of certain genetic profile. The presence of wild type KRAS is known to be positive efficacy biomarker for Cetuximab. The US Food and Drug Administration (FDA) updated the labels of Cetuximab to include information about KRAS mutations [5]. Such genetic testing often requires development of companion diagnostics to profile patient who is likely to respond positively when treated with targeted drugs [6], however, only large pharmaceutical companies have ventured in the area of companion diagnostics because of factors like cost, complex approval system [7]. Pharmaceutical companies involved in development of targeted therapies will have to invest more when compared with traditional drug development cost; moreover market size will be restricted to smaller patient population who would meet stringent genetic criteria. End-users will have to bear cost of such heavy investment associated with targeted therapies. Widespread use of such targeted drugs in case of oral cancer does not look feasible, since oral cancer is more prevalent in less developed countries in which patients cannot afford such costly treatment. Success of targeted therapy is often limited by acquired drug resistance [8-14], which essentially means constant evolution of targeted therapies.

Nature is a source of anti-cancer compounds which are used as preventive and/or curative agents which act as antioxidants, antiproliferative agents with general acceptance as a dietary element with a well-established safety profile. According to one of the estimates by World Health Organization approximately $80 \%$ of the world's population relies on traditional medicine for their primary health care [15]. Drugs derived from these natural sources have become potential source of alternative medicine which can be used along or in combination with chemotherapy/targeted drugs to manage cancer. Some of the compounds from various natural sources which have shown potential for prevention of oral carcinogenesis are curcumin [16], green tea extract [17,18], luteolin [19], genistein [20], ellagic acid [21], lycopene [22], betulinic acid [23], n-3 polyunsaturated fatty acids [24], hesperetin [25], and 13-cis-retinoic acid [26].

Ellagic acid (Figure 1) is a potent plant antioxidant $[27,28]$ and antiproliferative $[29,30]$ compound found in numerous fruits, nuts and vegetables including pomegranates, pecans, raspberries, strawberries, walnuts. Ellagic acid (EA) is derived from ellagitannins (ETs) present as dietary polyphenols found in fruits and nuts [31-33]. Ellagic acid

*Corresponding author: Professor P.S. Bisen, Emeritus Scientist, Defence Research Development Establishment, Defence Research Development Organisation, Ministry of Defence, Govt. of India, Jhansi Road, Gwalior 474002, India, E-mail: psbisen@gmail.com

Received December 17, 2011; Accepted February 07, 2012; Published February 09, 2012

Citation: Bisen PS, Bundela SS, Sharma A (2012) Ellagic Acid - Chemopreventive Role in Oral Cancer. J Cancer Sci Ther 4: 023-030. doi:10.4172/1948-5956.1000106

Copyright: (c) 2012 Bisen PS, et al. This is an open-access article distributed under the terms of the Creative Commons Attribution License, which permits unrestricted use, distribution, and reproduction in any medium, provided the original author and source are credited. 
is further metabolically converted into urolithins by intestinal microflora. The various pharmacological properties attributed to ellagic acid are due to ellagic acid alone, or their metabolite, or the combination of both, is still not precisely known.

The anti-proliferative properties of ellagic acid are due to its ability to directly inhibit the DNA binding of certain carcinogens, including polycyclic aromatic hydrocarbons [34], and nitrosamines [35-37]. Ellagic acid down-regulates insulin-like growth factor (IGF-II) [38] and activates expression of tumor suppressor genes $\mathrm{p} 53 / \mathrm{p} 21$, leading to cell cycle arrest at the G1/S phase and apoptosis [30]. Ellagic acid prevents carcinogen induced tumorigenesis by activating detoxifying enzymes [39] and inhibiting certain cytochrome P450 enzymes involved in the generation of mutagens [40,41].

Anticarcinogenic effect of ellagic acid have been reported in prostate [42], liver [43], colorectal [38], esophageal [44], bladder [45] and leukemia [46,47] cancer cell lines. Ellagic acid was reported to reduce chemotherapy induced toxicity in hormone refractory prostate cancer (HRPC) [48].

Ellagic acid was reported to inhibit 4-nitroquinoline-1-oxide (4-NQO)-induced tongue carcinogenesis in rat [49] and it also inhibited the growth of premalignant and malignant oral human cell-line [21]. Ohio State University scientists have demonstrated preventive role of ellagic acid in context for oral tumorigenesis [50], their research work is extended to clinical trial with an objective to understand mechanistic details of therapy and design alternative therapy for managing oral cancers [51]. The lyophilized black raspberries (LBRs), consisting of concentrates of nutrients including ellagic acid and anthocyanins, demonstrated to have a protective effect on chemically induced cancer in the hamster cheek pouch [50]. The localized delivery of LMRs with a mucoadhesive gel was evaluated in phase I study with a satisfactory result [52]. Further, the effects of topical application of the $10 \%$ black raspberry gel to oral intraepithelial neoplastic lesions in 17 patients and normal tissues in 10 patients was assessed [53]. The significant reduction in loss of heterozygosity at three tumor suppressor gene ( $\mathrm{p} 53$, CDKN2A, FHIT) loci with histological regression of the intraepithelial neoplastic lesions was observed. The efficacy of chemopreventive role of LBRs was corroborated by gene expression studies, in which reduced expression of COX-2, iNOS, and genes associated with inhibition of apoptosis, RNA processing, and growth factor recycling was observed [54]. The LBRs consist of ellagic acid along with various other nutrients;

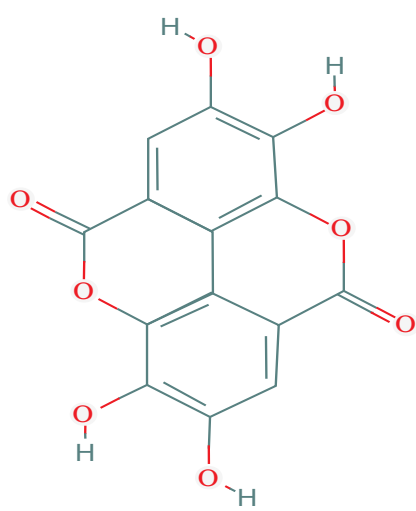

Figure 1: Chemical structure of ellagic acid. therefore caution should be used while assigning pharmacological activities of LBRs to ellagic acid alone. Therefore, future clinical trials are warranted to validate the chemopreventive role of ellagic acid in oral cancer.

This review aims to discuss molecular targets of ellagic acid possibly responsible for prevention of oral cancer and attempts to lay foundation for designing experiments to validate proposed molecular targets of ellagic acid in context of oral cancer.

\section{Molecular Targets}

The chemopreventive role of dietary polyphenols like ellagitannins (ETs) or ellagic acid (EA) can be understood by review of its molecular targets. There is no evidence till date to explain mechanistic details of chemopreventive role of EA in oral cancer (Figure 2). In absence of such direct evidences, we have attempted to propose inference based explanation for chemopreventive role of EA in oral cancer [21,49].

\section{Casein kinase 2 (CK2)}

Casein kinase II (CK2) is a constitutively active serine/threonine protein kinase which is proposed to have regulatory function in cell differentiation, cell proliferation, apoptosis and invasion [55-57]. CK2 can phosphorylate host of intracellular signaling proteins implicated in tumor suppression (p53 [58] and PTEN [59]), tumorigenesis (c-Myc [60], Jun [61], NF- $\mathrm{BB}$ [62]). Inhibition of CK2 is suggested to be an attractive therapeutic strategy to manage tumorigenesis in oral cancer $[63,64]$. Ellagic acid was reported to be a potent inhibitor of CK2 in virtual screening study [65]. The crystallographic structure of a-subunit of CK2 complexed with ellagic acid, has been submitted into the Protein Data Bank (PDB) with entry code of 2ZJW [66]. The availability of structural information should help in understanding details of ligand-receptor binding and thereby should enable rational drug designing [67].

\section{Telomerase reverse transcriptase (TERT)}

Telomerase is a ribonucleoprotein polymerase that maintains telomere ends by addition of the telomere repeat TTAGGG. The enzyme consists of a protein component with reverse transcriptase activity, encoded by this gene, and RNA component which serves as a template for the telomere repeat. The replicative potential of cell is limited by factors like senescence and crisis, which eventually leads to massive cell death by end-to-end fusion of chromosomes, with very rare variants having ability to multiply without limit; the process is termed as immortalization [68]. Telomerase activity is critical for controlling unlimited potential for division or immortalization $[69,70]$. Telomerase activity is not undetectable in normal somatic cells, however can be evaluated in biopsied tissue from oral cancer [71-73]. Recently, dendrimers-delivered shRNA targeting of hTERT has demonstrated to inhibit oral cancer cell growth [74]. Ellagic acid was reported to downregulate the 17beta-estradiol-induced hTERT expression [75].

\section{Growth factors signaling pathways}

Mitogenic growth signals are required by normal cells to move from quiescent state into an active proliferative state. In normal cell these mitogenic growth factors are made by one cell type in order to stimulate proliferation of another (heterotypic signaling), whereas cancer cells acquire the ability to synthesize growth factors necessary for its own proliferation (autocrine signaling). The suppression of 


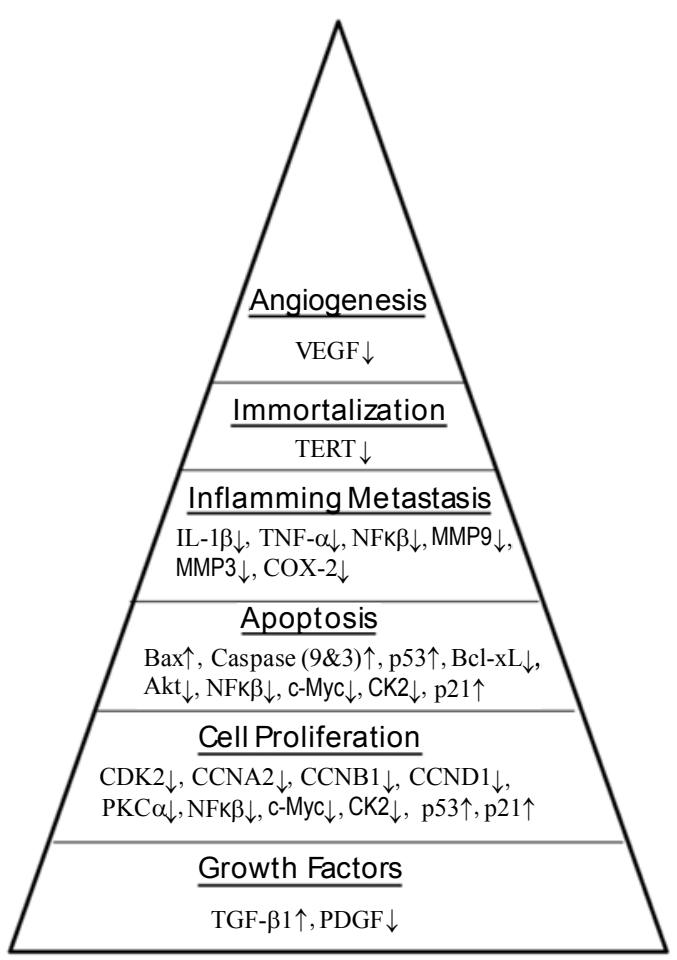

Figure 2: Schematic diagram indicating the plausible anti-cancer activity of ellagic acid. Modulation of targets from various cancer hallmarks by ellagic acid. Targets up-regulated is suffixed by $\uparrow$, those down-regulated are suffixed by $\downarrow$. TGF- $\beta 1$ transforming growth factor beta, PDGF platelet derived growth factor, CDK2 cyclin dependent kinase 2, CCNA2 cyclin A2, CCNB1 cyclin B1, CCND1 cyclin D1, PKCa protein kinase $\mathrm{C}$ alpha, Bax bcl2-associated $\mathrm{X}$ protein, p53 tumor protein p53, Bcl-xL bcl2-like 1, Akt v-akt murine thymoma viral oncogene homolog 1, NF-K $\beta$ Nuclear factor-kappa B, c-Myc v-myc myelocytomatosis viral oncogene homolog (avian), p21 cyclin-dependent kinase inhibitor $1 \mathrm{~A}$ (p21, Cip1), CK2 Casein kinase 2, TERT Telomerase reverse transcriptase, IL-1 beta interleukin 1, beta, TNF-alpha tumor necrosis factor, MMP9 matrix metalloproteinase 9, MMP3 matrix metalloproteinase 3, COX-2 prostaglandinendoperoxide synthase 2 (prostaglandin G/H synthase and cyclooxygenase), $V E G F$ vascular endothelial growth factor.

growth factors results in suppression of tumor growth. Growth factors implicated in oral carcinogenesis and targeted by ellagic acid are transforming growth factor- $\beta$ (TGF- $\beta 1$ ) [76] and platelet derived growth factor (PDGF) [77]. Ellagic acid improves expression of TGF- $\beta 1$, thereby promoting its tumor suppressing activity [78]. Ellagic acid down-regulates expression of PDGF, which is commonly overexpressed in oral cancer [79].

\section{Nuclear factor-kappa B (NF- $\kappa \beta)$}

NF- $\kappa \beta$ is a pleiotropic transcription factor found in all cell types. Under resting condition, the NF- $\kappa \beta$ dimers reside in cytoplasm. NF$\kappa \beta$ is activated by free radicals, cytokines, carcinogens, inflammatory stimuli, radiation, and endotoxins. Upon activation, it is translocated to the nucleus, where it activates expression of more than 400 genes [80] which are involved in various tumorigenic activities like survival, proliferation, invasion, metastasis, inflammation and resistance [8184]. NF- $\kappa \beta$ promotes cancer development by activating survival genes like $\mathrm{Bcl}-2, \mathrm{Bcl}-\mathrm{XL}$ and also induces expression of critical genes like matrix metalloproteases (MMP) and vascular endothelial growth factor (VEGF) involved in metastasis and angiogenesis. Ellagic acid is reported to be potent inhibitor of NF- $\kappa \beta[85,86]$. Ellagic acid induces apoptosis through inhibition of NF- $\kappa \beta[86]$.

\section{Cell cycle}

Cell cycle is tightly regulated event controlled through various check-points to maintain cellular integrity. Cyclin-dependent kinases (CDKs) are the key regulatory enzymes, each consisting of a catalytic CDK and activating cyclin subunits. CDKs regulate the cell's progression through the phases of the cell cycle by modulating the activity of key substrates. Regulatory proteins targeted by ellagic acid which are also implicated in oral carcinogenesis are cyclin dependent kinase 2 (CDK2) [87], cyclin A2 (CCNA2) [88], cyclin B1 (CCNB1) [89], cyclin D1 (CCND1) [90] and protein kinase C alpha (PKCa) [91]. Over expression of these regulatory proteins is hallmark of oral cancer. Ellagic acid induces G0/G1-phase arrest of the cell cycle by decreasing expression of CDK2 [45], S-phase cell cycle arrest by down-regulation of expression of cyclin A and B1 [92] and cell cycle arrest by downregulation of PKCa [76], cyclin D1 [77].

\section{Apoptosis and survival pathways}

Apoptosis is a cellular mechanism through which natural balance between cell death and cell renewal is maintained by killing damaged, excess, or abnormal cells. The programmed cell death or apoptosis is the mechanism which is triggered by a variety of physiologic signals like DNA damage, signaling imbalance, survival factor insufficiency, hypoxia [93-95], and followed by precise steps, by which cellular components are degraded and removed from the system in less than $24 \mathrm{hrs}$ [96]. Tumor cell have acquired ability to evade such apoptotic actions by promoting anti-apoptotic or survival mechanism. Ellagic acid promotes apoptosis in oral cancer cells, by activating pro-apoptotic genes like Bax [96], Caspase 9 [92], Caspase 3 [92,97] and inhibiting survival genes like Bcl-XL [92], Akt [97], NF-к $\beta$ [86].

\section{Inflaming metastasis pathways}

Metastasis is one of the adaptive mechanisms of tumor cells by which they migrate and invade adjacent tissues thereby travels to distant sites, to find new source of nutrients necessary for growth. Ability to metastasize is rendered to tumor cells with intrinsic properties and factors derived from tumor micro-environment such as inflammation $[98,99]$. Metastasis makes it very difficult to manage cancers, and is one of the most important contributors of deaths caused due to cancer. Ellagic acid inhibits pro-inflammatory cytokines (IL-1 beta [100], TNF-alpha [100]), matrix metalloproteinases (MMP9 [77], MMP2 [101]), COX-2 [77] in oral cancer cells, and there by abrogates metastasis induced by inflammation $[99,102,103]$.

\section{Angiogenesis}

Cell function and survival, critically depends on availability of oxygen and nutrients supplied by vasculature, obligating virtually all cells in a tissue to reside close to blood capillary system. Factors promoting growth of new blood vessels (angiogenesis) is imperative for tumorigenesis. Ellagic acid down-regulates vascular endothelial growth factor (VEGF) [77], a key regulator of angiogenic pathway in oral cancer. Ellagic acid down-regulates VEGF, through indirect pathway by modulating NF- $\kappa \beta$.

\section{Tumor-suppressor gene p53 and Proto-oncogene c-Myc}

p53 occupies critical place in a network of signaling pathways that are essential for regulation of cell growth and apoptosis induced 
by genotoxic and non-genotoxic stresses [104,105]. It activates the transcription of pro-apoptotic genes like p21WAF1 [106] and Bax [107] and therefore induces apoptosis.

The p53 induced apoptosis, typically follows intrinsic pathway, however it also modulates apoptosis through extrinsic pathway. p53 brings out apoptosis mainly through transcriptional regulation of apoptosis effectors genes. It activates transcription of various proapoptotic genes like Noxa, Puma, Bax, Bad, and Bim and is also involved in transcriptional repression of anti-apoptotic factors like survivin, Bcl-2, Bcl-XL. It induces apoptosis by transcriptional activation of APAF1 contributing towards formation of 'apoptosome' and also activates death receptors (TNF- $\alpha$, Fas, DR5), thereby promoting extrinsic pathway. Ellagic acid is known to increase expression of p53 and p21 [45] and induce cell cycle arrest and apoptosis.

c-Myc proto-oncogene is aberrantly expressed in oral cancer $[108,109]$. c-Myc promotes cell growth by inducing transcription of host of genes involved in cell cycle, apoptosis, DNA metabolism [110,111]. Ellagic acid inhibits cancer cell growth, by reducing the expression of c-Myc [77].

\section{Antioxidant}

Reactive oxygen species (ROS) are a major cause of cellular injury leading to pathogenesis of various diseases including cancer. The oxidative stress caused by the accumulation of ROS may cause mutagenesis, cytotoxicity and gene expression promoting carcinogenesis in oral cancer [112]. The increase in peroxidation of membrane lipid and ROS has been reported in oral cancer [113,114]. The anti-oxidant enzymes such as superoxide dismutases (SOD), catalase (CAT), glutathione peroxidase (GPX), limit cell injury induced by ROS. The activity of these anti-oxidant enzymes is reduced significantly in tissue samples collected from oral cancer patients $[115,116]$. Ellagic acid showed high DPPH free radical scavenging and lipid peroxidation inhibitory activities [97,117]. Ellagic acid activates anti-oxidant enzymes such as superoxide dismutases (SOD), catalase (CAT), and glutathione peroxidase (GPX) [97].

\section{Metabolism and Bioavailability}

Ellagitannins (ETs) are hydrolyzed to ellagic acid (EA) in vivo under physiological conditions. The presence of ellagic acid in human plasma with maximum concentration of $31.9 \mathrm{ng} / \mathrm{ml}$ after consumption of pomegranate juice was reported (at a dose containing $25 \mathrm{mg}$ ellagic acid and $318 \mathrm{mg}$ hydrolyzable ellagitannins) [118]. Ellagic acid is further progressively metabolized by intestinal microbiota into different types to urolithins (Figure 3) viz. urolithin D (UD), urolithin C (UC) and finally into urolithin A (UA) and urolithin B (UB) [119]. The urolithin A (UA) and urolithin B (UB) were reported to be the most prevalent metabolites of ellagic acid in human subjects, which persists up to 56 hrs after ingestion of ellagitannins [120-122].

It was observed in pharmacokinetic studies that when mice administered with pomegranate extract or urolithin A, metabolites of ellagitannin (ellagic acid and urolithin A) showed preference to be accumulated in certain organ systems like prostate, intestine and colon [123]. It was further reported that the main metabolite detected was urolithin A glucuronide, (3, 8-dihydroxy-6H-dibenzo[b,d]pyran-6one glucuronide) (up to $2 \mathrm{ng} / \mathrm{g}$ ) together with the traces of urolithin B glucuronide, (3-hydroxy-6H-dibenzo[b,d]pyran-6-one glucuronide) and dimethyl ellagic acid of ellagitanins in prostate gland among human subjects [124]. The low bioavailability of ellagic acid should be regarded as one of the major reasons why potent pharmacological activities reported during in vitro studies are not replicated in in vivo studies. The chemistry development kit (CDK) [125] was used to compute LogP of ellagic acid and urolithins to understand their bioavailabilities. The $\log \mathrm{P}$ is a standard parameter used to estimate lipophilicity of the test compound. The LogP values of urolithin A (UA) and urolithin B (UB) is more than zero and close to that required for optimum colonic absorption $(\log P=1.32)$, explaining their uptake from intestine and entry into systemic circulation.

Some of the pharmacological activities of ellagic acid can be attributed to its metabolic products (urolithins). The antioxidant activity of ellagitannins, ellagic acid and its intestinal microbial metabolites, was studied using a cell-based assay [126]. The urolithins

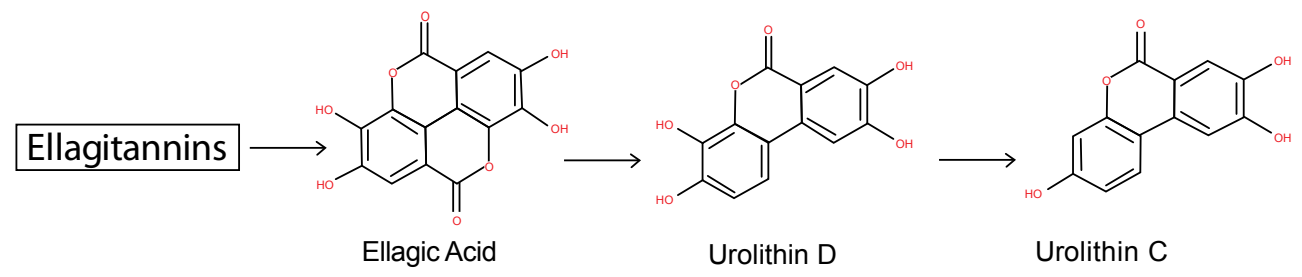

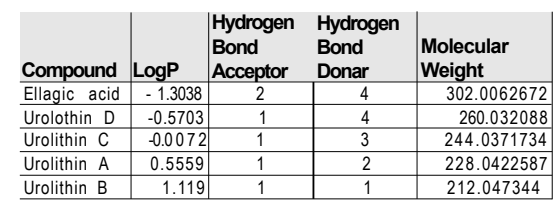

Figure 3: Metabolism of ellagic acid. Ellagitannins are derived from natural sources like fruits, nuts and vegetables. Ellagitannins are hydrolyzable polyphenols which are converted into ellagic acid in vivo under physiological conditions. Ellagic acid is further acted upon by intestinal microbiota, and consequently converted into Urolithin D, Urolithin C, Urolithin A, Urolithin B progressively. Physicochemical parameters of ellagic acid computed by chemistry development kit (CDK) are represented in the Table. 
were reported to possess stronger antioxidant activity when compared with parent ellagic acid and ellagitannins. The most potent antioxidants reported were urolithins $\mathrm{C}$ and $\mathrm{D}$ with IC (50) values of 0.16 and 0.33 microM, respectively, when compared to IC (50) values of 1.1 and 1.4 microM of the parent ellagic acid and punicalagins, respectively. The dihydroxylated urolithin A showed weaker antioxidant activity, with an IC (50) value 13.6 microM, however, the potency was within the range of urolithin A plasma concentrations. The anti-inflammatory and antioxidant activity of urolithin A was also reported in an in vivo study [127]. The Urolithin B was reported to have potent anti estogenic activity [128].

\section{Conclusion}

Oral cancer develops by complex interplay between intrinsic and extrinsic factors playing important role in tumor development from primary lesion. The process of expression of tumorigenesis is based on a tightly controlled sequence of events which are dependent on the proper levels of transcription and translation of certain genes. There is a small subset that seems to be particularly important in the prevention, development, and progression of cancer. These genes have been found to be either malfunctioning or non-functioning in oral cancer. It is, therefore, logical to believe that success of any therapy will depend on its effectiveness to modulate these genes controlling different pathways to restore homeostasis. Molecular targets of ellagic acid are the key regulators, spread across all cancer hallmarks, which should make it an effective agent for prevention of oral cancer. Ellagic acid is known to modulate key regulators like NF- $\kappa \beta$, p 53 and CK2. The versatility of EA to inhibit oral carcinogenesis through multiple pathways makes ellagic acid a potent chemopreventive agent $[129,130]$.

Low bioavailability of ellagic acid could be one of the major reasons why it was not researched for chemoprevention of oral cancer. The focus of current research has moved to bioavailable metabolites of ellagic acid. We have attempted to present inference based framework to explain role of ellagic acid in prevention of oral carcinogenesis. Structural optimization of ellagic acid to improve its bioavailability does not look promising strategy, as any structural change may significantly alter its anticarcinogenic actions [131]. Advancements in the field of targeted drug delivery system can be used to overcome this challenge [132]. Feasibility of functionalized graphene oxide as nanocarrier for ellagic acid was reported [133]. With this encouraging development in the area of targeted drug delivery system, now it has become possible to design experiments, to understand the pharmacological properties of ellagic acid and its metabolites like urolithins, administered separately or in combination. Such experiments should act as guide to plan clinical trials for testing efficacy of ellagic acid in prevention of oral cancer.

\section{Acknowledgment}

We wish to express our gratitude to Council of Scientific and Industrial Research (CSIR), New Delhi for the award of Emeritus Scientist to Prof. P.S. Bisen and to Professor Dr. M.P. Kaushik, Director and Dr. S.J.S. Flora, Associate Director, Defence Research Development Establishment, Defence Research Development Organization, Ministry of Defence, Govt. Of India, Jhansi Road, Gwalior 474002, India, and Head, Department of Postgraduate Studies and Research in Biological Sciences, R.D. University, Jabalpur, India for extending necessary facilities.

\section{References}

1. Ferlay J, Shin HR, Bray F, Forman D, Mathers C et al. (2008) Cancer Incidence and Mortality Worldwide: IARC Cancer Base No. 10.

2. Wake M (1993) The urban/rural divide in head and neck cancer--the effect of atmospheric pollution. Clin Otolaryngol Allied Sci 18: 298-302.
3. Massano J, Regateiro FS, Januario G, Ferreira A (2006) Oral squamous cell carcinoma: Review of prognostic and predictive factors. Oral Surg Oral Med Oral Pathol Oral Radiol Endod 102: 67-76.

4. Cetuximab (Erbitux®) (2009) Plus Radiation Beneficial in Head and Neck Cancer - National Cancer Institute.

5. Class Labeling Changes to anti-EGFR monoclonal antibodies, cetuximab (Erbitux) and panitumumab (Vectibix): KRAS Mutations.

6. August J (2010) Market watch: Emerging companion diagnostics for cancer drugs. Nat Rev Drug Discov 9: 351.

7. Schmidt C (2011) Larger companies dominate cancer companion diagnostic approvals. Nat Biotechnol 29: 955-957.

8. Foo J, Michor F (2009) Evolution of resistance to targeted anti-cancer therapies during continuous and pulsed administration strategies. PLoS Comput Biol 5 : e1000557.

9. Gorre M, Mohammed M, Ellwood K, Hsu N, Paquette R, et al. (2001) Clinical resistance to sti-571 cancer therapy caused by bcr-abl gene mutation or amplification. Science 293: 876-880.

10. Vogt PK (2008) Drug-resistant phosphatidylinositol 3-kinase: guidance for the preemptive strike. Cancer Cell 14: 107-108.

11. Pao W, Miller VA, Politi KA, Riely GJ, Somwar R, et al. (2005) Acquired resistance of lung adenocarcinomas to gefitinib or erlotinib is associated with a second mutation in the EGFR kinase domain. PLoS Med 2: e73.

12. Bentires-Alj M, Barbu V, Fillet M, Chariot A, Relic B, et al. (2003) NF-kappaB transcription factor induces drug resistance through MDR1 expression in cancer cells. Oncogene 22: 90-97.

13. Chiang CS, Sawyers CL, Mcbride WH (1998) Oncogene expression and cellular radiation resistance: A modulatory role for c-myc. Mol Diagn 3: 21-27.

14. Dowsett M (2001) Overexpression of her-2 as a resistance mechanism to hormonal therapy for breast cancer. Endocr Relat Cancer 8: 191-195.

15. Farnsworth NR, Akerele O, Bingel AS, Soejarto DD, Guo Z (1985) Medicina plants in therapy. Bull World Health Organ 63: 965-981.

16. Li N, Chen X, Liao J, Yang G, Wang S, et al. (2002) Inhibition of 7,12-dimethylbenz[a]anthracene (DMBA)-induced oral carcinogenesis in hamsters by tea and curcumin. Carcinogenesis 23: 1307-1313.

17. Zhang X, Zhang H, Tighiouart M, Lee JE, Shin HJ, et al. (2008) Synergistic inhibition of head and neck tumor growth by green tea (-)-epigallocatechin-3gallate and EGFR tyrosine kinase inhibitor. Int J Cancer 123: 1005-1014.

18. Khafif A, Schantz SP, Chou TC, Edelstein D, Sacks PG (1998) Quantitation of chemopreventive synergism between (-)-epigallocatechin-3-gallate and curcumin in normal, premalignant and malignant human oral epithelial cells. Carcinogenesis 19: 419-424.

19. Yang SF, Yang WE, Chang HR, Chu SC, Hsieh YS (2008) Luteolin induces apoptosis in oral squamous cancer cells. J Dent Res 87: 401-406.

20. Yang Y, Zhou ZT, Ge JP (2006) Effect of genistein on DMBA-induced ora carcinogenesis in hamster. Carcinogenesis 27: 578-583.

21. Han C, Ding H, Casto B, Stoner GD, D'Ambrosio SM (2005) Inhibition of the growth of premalignant and malignant human oral cell lines by extracts and components of black raspberries. Nutr Cancer 51: 207-217.

22. Lu R, Dan H, Wu R, Meng W, Liu N, et al. (2011) Lycopene: features and potential significance in the oral cancer and precancerous lesions. J Ora Pathol Med 40: 361-368.

23. Thurnher D, Turhani D, Pelzmann M, Wannemacher B, Knerer B, et al. (2003) Betulinic acid: a new cytotoxic compound against malignant head and neck cancer cells. Head Neck 25: 732-740.

24. Actis AB, López CB, Joekes S, Eynard AR (1999) N-3, n-6 and n-9 dietary fatty acids modulate the growth parameters of murine salivary gland tumors induced by dimethylbenzanthracene. Prostaglandins Leukot Essent Fatty Acids 61 : 259-265.

25. Miller EG, Peacock JJ, Bourland TC, Taylor SE, Wright JM, et al. (2008) Inhibition of oral carcinogenesis by citrus flavonoids. Nutr Cancer 60: 69-74. 
26. Hong WK, Endicott J, Itri LM, Doos W, Batsakis JG, et al. (1986) 13-cis-retinoic acid in the treatment of oral leukoplakia. N Engl J Med 315: 1501-1505.

27. Atta-Ur-Rahman, Ngounou FN, Choudhary MI, Malik S, Makhmoor T, et al. (2001) New antioxidant and antimicrobial ellagic acid derivatives from Pteleopsis hylodendron. Planta Med 67: 335-339

28. Festa F, Aglitti T, Duranti G, Ricordy R, Perticone P, et al. (2001) Strong antioxidant activity of ellagic acid in mammalian cells in vitro revealed by the comet assay. Anticancer Res 21: 3903-3908

29. Seeram NP, Adams LS, Henning SM, Niu Y, Zhang Y, et al. (2005) In vitro antiproliferative, apoptotic and antioxidant activities of punicalagin, ellagic acid and a total pomegranate tannin extract are enhanced in combination with other polyphenols as found in pomegranate juice. J Nutr Biochem 16: 360-367.

30. Narayanan BA, Geoffroy O, Willingham MC, Re GG, Nixon DW (1999) p53/ p21(WAF1/CIP1) expression and its possible role in G1 arrest and apoptosis in ellagic acid treated cancer cells. Cancer Lett 136: 215-221.

31. Leonardo S, Alberto A, Raul RH, Antonio AC, Cristobal NA (2011) Ellagic acid: Biological properties and biotechnological development for production processes. Afr J Biotechnol 10: 4518-4523.

32. Boukharta M, Jalbert G, Castonguay A (1992) Biodistribution of ellagic acid and dose-related inhibition of lung tumorigenesis in $\mathrm{A} / \mathrm{J}$ mice. Nutr Cancer 18: 181-189.

33. Doyle B, Griffiths LA (1980) The metabolism of ellagic acid in the rat. Xenobiotica 10: 247-256.

34. Teel RW, Babcock MS, Dixit R, Stoner GD (1986) Ellagic acid toxicity and interaction with benzo[a]pyrene and benzo[a]pyrene 7,8-dihydrodiol in human bronchial epithelial cells. Cell Biol Toxicol 2: 53-62.

35. Mandal S, Stoner GD (1990) Inhibition of N-nitrosobenzylmethylamine-induced esophageal tumorigenesis in rats by ellagic acid. Carcinogenesis 11: 55-61.

36. Mandal S, Shivapurkar NM, Galati AJ, Stoner GD (1988) Inhibition of $\mathrm{N}$-nitrosobenzylmethylamine metabolism and DNA binding in cultured rat esophagus by ellagic acid. Carcinogenesis 9: 1313-1316.

37. Siglin JC, Barch DH, Stoner GD (1995) Effects of dietary phenethy isothiocyanate, ellagic acid, sulindac and calcium on the induction and progression of $\mathrm{N}$-nitrosomethylbenzylamine-induced esophageal carcinogenesis in rats. Carcinogenesis 16: 1101-1106.

38. Narayanan BA, Re GG (2001) IGF-II down regulation associated cell cycle arrest in colon cancer cells exposed to phenolic antioxidant ellagic acid. Anticancer Res 21: 359-364.

39. Barch DH, Rundhaugen LM (1994) Ellagic acid induces NAD(P)H:quinone reductase through activation of the antioxidant responsive element of the rat $\mathrm{NAD}(\mathrm{P}) \mathrm{H}$ :quinone reductase gene. Carcinogenesis 15: 2065-2068.

40. Zhang Z, Hamilton SM, Stewart C, Strother A, Teel RW (1993) Inhibition of liver microsomal cytochrome P450 activity and metabolism of the tobacco-specific nitrosamine NNK by capsaicin and ellagic acid. Anticancer Res 13: 2341-2346.

41. Barch DH, Rundhaugen LM, Thomas PE, Kardos P, Pillay NS (1994) Dietary ellagic acid inhibits the enzymatic activity of CYP1A1 without altering hepatic concentrations of CYP1A1 or CYP1A1 mRNA. Biochem Biophys Res Commun 201: 1477-1482.

42. Narayanan BA, Narayanan NK, Stoner GD, Bullock BP (2002) Interactive gene expression pattern in prostate cancer cells exposed to phenolic antioxidants. Life Sci 70: 1821-1839.

43. Tanaka T, Iwata H, Niwa K, Mori Y, Mori H (1988) Inhibitory effect of ellagic acid on $\mathrm{N}$-2-fluorenylacetamide-induced liver carcinogenesis in male $\mathrm{ACI} / \mathrm{N}$ rats. Jpn J Cancer Res 79: 1297-1303.

44. Stoner GD, Kresty LA, Carlton PS, Siglin JC, Morse MA (1999) Isothiocyanates and freeze-dried strawberries as inhibitors of esophageal cancer. Toxicol Sci 52: $95-100$.

45. Li TM, Chen GW, Su CC, Lin JG, Yeh CC, et al. (2005) Ellagic acid induced p53/p21 expression, G1 arrest and apoptosis in human bladder cancer T24 cells. Anticancer Res 25: 971-979.

46. Mertens-Talcott SU, Percival SS (2005) Ellagic acid and quercetin interact synergistically with resveratrol in the induction of apoptosis and cause transient cell cycle arrest in human leukemia cells. Cancer Lett 218: 141-151.

47. Hagiwara Y, Kasukabe T, Kaneko Y, Niitsu N, Okabe-Kado J (2010) Ellagic acid, a natural polyphenolic compound, induces apoptosis and potentiates retinoic acid-induced differentiation of human leukemia HL-60 cells. Int $J$ Hematol 92: 136-143.

48. Falsaperla M, Morgia G, Tartarone A, Ardito R, Romano G (2005) Support ellagic acid therapy in patients with hormone refractory prostate cancer (HRPC) on standard chemotherapy using vinorelbine and estramustine phosphate. Eur Urol 47: 449-454.

49. Tanaka T, Kojima T, Kawamori T, Wang A, Suzui M, et al. (1993) Inhibition of 4-nitroquinoline-1-oxide-induced rat tongue carcinogenesis by the naturally occurring plant phenolics caffeic, ellagic, chlorogenic and ferulic acids. Carcinogenesis 14: 1321-1325.

50. Casto BC, Kresty LA, Kraly CL, Pearl DK, Knobloch TJ, et al. (2002) Chemoprevention of oral cancer by black raspberries. Anticancer Res 22 4005-4015.

51. Lyophilized black raspberries in preventing oral cancer in high-risk patients previously diagnosed with stage I-IV or in situ head and neck cancer.

52. Mallery SR, Stoner GD, Larsen PE, Fields HW, Rodrigo KA, et al. (2007) Formulation and in-vitro and in-vivo evaluation of a mucoadhesive gel containing freeze dried black raspberries: implications for oral cancer chemoprevention. Pharm Res 24: 728-737.

53. Shumway BS, Kresty LA, Larsen PE, Zwick JC, Lu B, et al. (2008) Effects of a topically applied bioadhesive berry gel on loss of heterozygosity indices in premalignant oral lesions. Clin Cancer Res 14: 2421-2430.

54. Mallery SR, Zwick JC, Pei P, Tong M, Larsen PE, et al. (2008) Topica application of a bioadhesive black raspberry gel modulates gene expression and reduces cyclooxygenase 2 protein in human premalignant oral lesions. Cancer Res 68: 4945-4957.

55. Zheng Y, Qin H, Frank SJ, Deng L, Litchfield DW, et al. (2011) A CK2 dependent mechanism for activation of the JAK-STAT signaling pathway. Blood 118: 156-166.

56. Drygin D, Ho CB, Omori M, Bliesath J, Proffitt C, et al. (2011) Protein kinase CK2 modulates IL-6 expression in inflammatory breast cancer. Biochem Biophys Res Commun 415: 163-167.

57. Zou J, Luo H, Zeng Q, Dong Z, Wu D, et al. (2011) Protein kinase CK2 $\alpha$ is overexpressed in colorectal cancer and modulates cell proliferation and invasion via regulating EMT-related genes. J Transl Med 9: 97.

58. Meek DW, Cox M (2011) Induction and activation of the p53 pathway: a role for the protein kinase CK2? Mol Cell Biochem 356: 133-138.

59. Barata JT (2011) The impact of PTEN regulation by CK2 on PI3K-dependent signaling and leukemia cell survival. Adv Enzyme Regul 51: 37-49.

60. Channavajhala P, Seldin DC (2002) Functional interaction of protein kinase CK2 and c-Myc in lymphomagenesis. Oncogene 21: 5280-5288.

61. Torrecilla I, Spragg EJ, Poulin B, McWilliams PJ, Mistry SC, et al. (2007) Phosphorylation and regulation of a $\mathrm{G}$ protein-coupled receptor by protein kinase CK2. J Cell Biol 177: 127-137.

62. Romieu-Mourez R, Landesman-Bollag E, Seldin DC, Sonenshein GE (2002) Protein kinase CK2 promotes aberrant activation of nuclear factor-kappaB transformed phenotype, and survival of breast cancer cells. Cancer Res 62 6770-6778.

63. Faust RA, Tawfic S, Davis AT, Bubash LA, Ahmed K (2000) Antisense oligonucleotides against protein kinase CK2-alpha inhibit growth of squamous cell carcinoma of the head and neck in vitro. Head Neck 22: 341-346.

64. Brown MS, Diallo OT, Hu M, Ehsanian R, Yang X, et al. (2010) CK2 modulation of NF-kappaB, TP53, and the malignant phenotype in head and neck cancer by anti-CK2 oligonucleotides in vitro or in vivo via sub-50-nm nanocapsules. Clin Cancer Res 16: 2295-2307.

65. Cozza G, Bonvini P, Zorzi E, Poletto G, Pagano MA, et al. (2006) Identification of ellagic acid as potent inhibitor of protein kinase CK2: a successful example of a virtual screening application. J Med Chem 49: 2363-2366. 
66. Sekiguchi Y, Nakaniwa T, Kinoshita T, Nakanishi I, Kitaura K, et al. (2009) Structural insight into human CK2alpha in complex with the potent inhibitor ellagic acid. Bioorg Med Chem Lett 19: 2920-2923.

67. Cozza G, Gianoncelli A, Bonvini P, Zorzi E, Pasquale R, et al. (2011) Urolithin as a converging scaffold linking ellagic acid and coumarin analogues: design of potent protein kinase CK2 inhibitors. ChemMedChem 6: 2273-2286.

68. Wright WE, Pereira-Smith OM, Shay JW (1989) Reversible cellular senescence: implications for immortalization of normal human diploid fibroblasts. Mol Cell Biol 9: 3088-3092.

69. Schliephake H (2003) Prognostic relevance of molecular markers of oral cancer--a review. Int J Oral Maxillofac Surg 32: 233-245.

70. Ries JC, Hassfurther E, Steininger H, Kloss FR, Wiltfang J, et al. (2001) Correlation of telomerase activity, clinical prognosis and therapy in oral carcinogenesis. Anticancer Res 21: 1057-1063.

71. Liao J, Mitsuyasu T, Yamane K, Ohishi M (2000) Telomerase activity in ora and maxillofacial tumors. Oral Oncol 36: 347-352.

72. Freier K, Pungs S, Flechtenmacher C, Bosch FX, Lichter P, et al. (2007) Frequent high telomerase reverse transcriptase expression in primary oral squamous cell carcinoma. J Oral Pathol Med 36: 267-272.

73. Miyoshi Y, Tsukinoki K, Imaizumi T, Yamada Y, Ishizaki T, et al. (1999) Telomerase activity in oral cancer. Oral Oncol 35: 283-289.

74. Liu X, Huang H, Wang J, Wang C, Wang M, et al. (2011) Dendrimers-delivered short hairpin RNA targeting hTERT inhibits oral cancer cell growth in vitro and in vivo. Biochem Pharmacol 82: 17-23.

75. Strati A, Papoutsi Z, Lianidou E, Moutsatsou P (2009) Effect of ellagic acid on the expression of human telomerase reverse transcriptase (hTERT) alpha+beta+ transcript in estrogen receptor-positive MCF-7 breast cancer cells. Clin Biochem 42: 1358-1362.

76. Mishra S, Vinayak M (2011) Anti-carcinogenic action of ellagic acid mediated via modulation of oxidative stress regulated genes in Dalton lymphoma bearing mice. Leuk Lymphoma 52: 2155-2161.

77. Aggarwal BB, Shishodia S (2006) Molecular targets of dietary agents for prevention and therapy of cancer. Biochem Pharmacol 71: 1397-1421.

78. Paterson IC, Davies M, Stone A, Huntley S, Smith E, et al. (2002) TGF-beta1 acts as a tumor suppressor of human malignant keratinocytes independently of Smad 4 expression and ligand-induced G(1) arrest. Oncogene 21: 1616-1624.

79. Mishima K, Inoue K, Hayashi Y (2002) Overexpression of extracellular-signal regulated kinases on oral squamous cell carcinoma. Oral Oncol 38: 468-474.

80. Sung B, Pandey MK, Ahn KS, Yi T, Chaturvedi MM, et al. (2008) Anacardic acid (6-nonadecyl salicylic acid), an inhibitor of histone acetyltransferase suppresses expression of nuclear factor-kappaB-regulated gene products involved in cell survival, proliferation, invasion, and inflammation through inhibition of the inhibitory subunit of nuclear factor-kappaBalpha kinase, leading to potentiation of apoptosis. Blood 111: 4880-4891.

81. Nariai Y, Mishima K, Yoshimura Y, Sekine J (2011) FAP-1 and NF-KB expressions in oral squamous cell carcinoma as potential markers for chemoradio sensitivity and prognosis. Int J Oral Maxillofac Surg 40: 419-426.

82. Rao SK, Pavicevic Z, Du Z, Kim JG, Fan M, et al. (2010) Pro-inflammatory genes as biomarkers and therapeutic targets in oral squamous cell carcinoma. J Biol Chem 285: 32512-32521.

83. Sun ZJ, Chen G, Hu X, Zhang W, Liu Y, et al. (2010) Activation of PI3K/Akt/IKKalpha/NF-kappaB signaling pathway is required for the apoptosis-evasion in human salivary adenoid cystic carcinoma: its inhibition by quercetin. Apoptosis 15: $850-863$

84. Zhang J, Peng B (2009) NF-kappaB promotes iNOS and VEGF expression in salivary gland adenoid cystic carcinoma cells and enhances endothelial cell motility in vitro. Cell Prolif 42: 150-161.

85. Romier B, Van De Walle J, During A, Larondelle Y, Schneider YJ (2008) Modulation of signalling nuclear factor-kappaB activation pathway by polyphenols in human intestinal Caco-2 cells. Br J Nutr 100: 542-551.
86. Edderkaoui M, Odinokova I, Ohno I, Gukovsky I, Go VL, et al. (2008) Ellagic acid induces apoptosis through inhibition of nuclear factor kappa B in pancreatic cancer cells. World J Gastroenterol 14: 3672-3680.

87. Mihara M, Shintani S, Nakahara Y, Kiyota A, Ueyama Y, et al. (2001) Overexpression of CDK2 is a prognostic indicator of oral cancer progression. Jpn J Cancer Res 92: 352-360.

88. Hiroi M, Mori K, Sekine K, Sakaeda Y, Shimada J, et al. (2009) Mechanisms of resistance to interferon-gamma-mediated cell growth arrest in human ora squamous carcinoma cells. J Biol Chem 284: 24869-24880.

89. Watanabe S, Watanabe R, Oton-Leite AF, Alencar Rde C, Oliveira JC, et al. (2010) Analysis of cell proliferation and pattern of invasion in oral squamous cell carcinoma. J Oral Sci 52: 417-424.

90. Xu J, Gimenez-Conti IB, Cunningham JE, Collet AM, Luna MA, et al. (1998) Alterations of $\mathrm{p} 53$, cyclin $\mathrm{D} 1, \mathrm{Rb}$, and $\mathrm{H}$-ras in human oral carcinomas related to tobacco use. Cancer 83: 204-212.

91. Cohen EE, Zhu H, Lingen MW, Martin LE, Kuo WL, et al. (2009) A feed-forward loop involving protein kinase $\mathrm{C}$ alpha and microRNAs regulates tumor cell cycle. Cancer Res 69: 65-74.

92. Larrosa M, Tomás-Barberán FA, Espín JC (2006) The dietary hydrolysable tannin punicalagin releases ellagic acid that induces apoptosis in human colon adenocarcinoma Caco-2 cells by using the mitochondrial pathway. J Nutr Biochem 17: 611-625.

93. Evan G, Littlewood T (1998) A matter of life and cell death. Science 281: 1317 1322.

94. Ishizaki Y, Cheng L, Mudge AW, Raff MC (1995) Programmed cell death by default in embryonic cells, fibroblasts, and cancer cells. Mol Biol Cell 6: 1443 1458.

95. Giancotti FG, Ruoslahti E (1999) Integrin signaling. Science 285: 1028-1033

96. Wyllie AH, Kerr JFR, Currie AR (1980) Cell death: the significance of apoptosis Int Rev Cytol 68: 251-306.

97. Han DH, Lee MJ, Kim JH (2006) Antioxidant and apoptosis-inducing activities of ellagic acid. Anticancer Res 26: 3601-3606.

98. Mantovani A, Allavena P, Sica A, Balkwill F (2002) Cancer-related inflammation. Nature 454: 436-444

99. Coussens LM, Werb Z (2002) Inflammation and cancer. Nature 420: 860-867.

100. Masamune A, Satoh M, Kikuta K, Suzuki N, Satoh K, et al. (2005) Ellagic acid blocks activation of pancreatic stellate cells. Biochem Pharmacol 70: 869-878.

101. Huang ST, Yang RC, Wu HT, Wang CN, Pang JH (2011) Zinc-chelation contributes to the anti-angiogenic effect of ellagic acid on inhibiting MMP-2 activity, cell migration and tube formation. PLoS One 6: e18986.

102. Giavazzi R, Garofalo A, Bani MR, Abbate M, Ghezzi P, et al. (1990) Interleukin 1-induced augmentation of experimental metastases from a human melanoma in nude mice. Cancer Res 50: 4771-4775.

103. Luo JL, Tan W, Ricono JM, Korchynskyi O, Zhang M, et al. (2007) Nuclear cytokine-activated IKKalpha controls prostate cancer metastasis by repressing Maspin. Nature 446: 690-694.

104. Vogelstein B, Lane D, Levine AJ (2000) Surfing the p53 network. Nature 408 307-310.

105. Vousden KH, Lu X (2002) Live or let die: the cell's response to p53. Nat Rev Cancer 2: 594-604.

106. el-Deiry WS, Tokino T, Velculescu VE, Levy DB, Parsons R, et al. (1993) WAF1, a potential mediator of p53 tumor suppression. Cell 75: 817-825.

107. Vogelstein B, Kinzler KW (1992) p53 function and dysfunction. Cell 70: 523526.

108.Pérez-Sayáns $M$, Suárez-Peñaranda JM, Pilar GD, Barros-Angueira $F$, Gándara-Rey JM, et al. (2011) What real influence does the proto-oncogene c-myc have in OSCC behavior? Oral Oncol 47: 688-692.

109. Martín-Ezquerra G, Salgado R, Toll A, Gilaberte M, Baró T, et al. (2010) Multiple genetic copy number alterations in oral squamous cell carcinoma: 
Citation: Bisen PS, Bundela SS, Sharma A (2012) Ellagic Acid - Chemopreventive Role in Oral Cancer. J Cancer Sci Ther 4: 023-030. doi:10.4172/19485956.1000106

study of MYC, TP53, CCDN1, EGFR and ERBB2 status in primary and metastatic tumours. Br J Dermatol 163: 1028-1035.

110. Dang CV (1999) c-Myc target genes involved in cell growth, apoptosis, and metabolism. Mol Cell Biol 19: 1-11.

111. Whitfield JR, Soucek L (2011) Tumor microenvironment: becoming sick of Myc. Cell Mol Life Sci [Epub ahead of print]

112. Sasabe E, Yang Z, Ohno S, Yamamoto T (2010) Reactive oxygen species produced by the knockdown of manganese-superoxide dismutase up-regulate hypoxia-inducible factor-1alpha expression in oral squamous cell carcinoma cells. Free Radic Biol Med 48: 1321-1329.

113. Rasheed MH, Beevi SS, Geetha A (2007) Enhanced lipid peroxidation and nitric oxide products with deranged antioxidant status in patients with head and neck squamous cell carcinoma. Oral Oncol 43: 333-338.

114. Manoharan S, Kolanjiappan K, Suresh K, Panjamurthy K (2005) Lipid peroxidation \& antioxidants status in patients with oral squamous cell carcinoma. Indian J Med Res 122: 529-534.

115. Yang J, Lam EW, Hammad HM, Oberley TD, Oberley LW (2002) Antioxidant enzyme levels in oral squamous cell carcinoma and normal human oral epithelium. J Oral Pathol Med 31: 71-77.

116. Gokul S, Patil VS, Jailkhani R, Hallikeri K, Kattappagari KK (2010) Oxidantantioxidant status in blood and tumor tissue of oral squamous cell carcinoma patients. Oral Dis 16: 29-33.

117. Lee SE, Shin HT, Hwang HJ, Kim JH (2003) Antioxidant activity of extract from Alpinia katsumadai seed. Phytother Res 17: 1041-1047.

118. Seeram NP, Lee R, Heber D (2004) Bioavailability of ellagic acid in human plasma after consumption of ellagitannins from pomegranate (Punica granatum L.) juice. Clin Chim Acta 348: 63-68.

119. Espín JC, González-Barrio R, Cerdá B, López-Bote C, Rey Al, et al. (2007) The Iberian pig as model to clarify obscure points in the bioavailability and metabolism of ellagitannins in humans. J Agric Food Chem 55: 10476-10485.

120. Seeram NP, Henning SM, Zhang Y, Suchard M, Li Z, et al. (2006) Pomegranate juice ellagitannin metabolites are present in human plasma and some persist in urine for up to 48 hours. J Nutr 136: 2481-2485.

121. Cerdá B, Espín JC, Parra S, Martínez P, Tomás-Barberán FA (2004) The poten in vitro antioxidant ellagitannins from pomegranate juice are metabolised into bioavailable but poor antioxidant hydroxy-6H-dibenzopyran-6-one derivatives by the colonic microflora of healthy humans. Eur J Nutr 43: 205-220.

122. Cerdá B, Tomás-Barberán FA, Espín JC (2005) Metabolism of antioxidant and chemopreventive ellagitannins from strawberries, raspberries, walnuts, and oak-aged wine in humans: identification of biomarkers and individual variability. J Agric Food Chem 53: 227-235

123. Seeram NP, Aronson WJ, Zhang Y, Henning SM, Moro A, et al. (2007) Pomegranate ellagitannin-derived metabolites inhibit prostate cancer growth and localize to the mouse prostate gland. J Agric Food Chem 55: 7732-7737.

124. González-Sarrías A, Giménez-Bastida JA, García-Conesa MT, GómezSánchez MB, García-Talavera NV, et al. (2010) Occurrence of urolithins, gut microbiota ellagic acid metabolites and proliferation markers expression response in the human prostate gland upon consumption of walnuts and pomegranate juice. Mol Nutr Food Res 54: 311-322.

125. Steinbeck C, Han Y, Kuhn S, Horlacher O, Luttmann E, et al. (2003) The Chemistry Development Kit (CDK): an open-source Java library for Chemo and Bioinformatics. J Chem Inf Comput Sci 43: 493-500.

126. Bialonska D, Kasimsetty SG, Khan SI, Ferreira D (2009) Urolithins, intestinal microbial metabolites of Pomegranate ellagitannins, exhibit potent antioxidant activity in a cell-based assay. J Agric Food Chem 57: 10181-10186.

127. Ishimoto H, Shibata M, Myojin $Y$, Ito H, Sugimoto $Y$, et al. (2011) In vivo antiinflammatory and antioxidant properties of ellagitannin metabolite urolithin A Bioorg Med Chem Lett 21: 5901-5904.

128. Adams LS, Zhang Y, Seeram NP, Heber D, Chen S (2010) Pomegranate ellagitannin-derived compounds exhibit antiproliferative and antiaromatase activity in breast cancer cells in vitro. Cancer Prev Res (Phila) 3: 108-113.

129. Hanahan D, Weinberg RA (2000) The hallmarks of cancer. Cell 100: 57-70.

130. Mantovani A (2009) Cancer: Inflaming metastasis. Nature 457: 36-37.

131. Barch DH, Rundhaugen LM, Stoner GD, Pillay NS, Rosche WA (1996) Structure-function relationships of the dietary anticarcinogen ellagic acid. Carcinogenesis 17: 265-269.

132. Allen TM, Cullis PR (2004) Drug delivery systems: entering the mainstream. Science 303: 1818-1822.

133. Kakran M, G Sahoo N, Bao H, Pan Y, Li L (2011) Functionalized graphene oxide as nanocarrier for loading and delivery of ellagic acid. Curr Med Chem 18: $4503-4512$ 